\title{
Glomerular Permselectivity in Proteinuric Patients after Kidney Transplantation
}

Rainer Oberbauer, Martin Haas, Heinz Regele, ${ }^{\star}$ Ursula Barnas, Alice Schmidt, and Gert Mayer

Department of Internal Medicine III, Division of Nephrology and Dialysis; and *Department of Pathology, Division of Ultrastructural

Pathology and Cell Biology, University of Vienna, 1090 Vienna, Austria

\begin{abstract}
To characterize the defect in glomerular permselectivity responsible for proteinuria after renal transplantation, we studied 10 patients with moderate proteinuria (median 0.37 g/d, range 0.20-0.79), 16 patients with the nephrotic syndrome (6.73 $\mathrm{g} / \mathrm{d}, 3.9-14.6), 8$ living related donor transplant recipients without any history of rejection (median proteinuria $0.26 \mathrm{~g} / \mathrm{d}, 0.06-0.58$ ), and 12 healthy volunteers. The fractional clearance of neutral dextrans $>54 \AA$ was significantly higher in nephrotic patients, demonstrating a defect in glomerular size selectivity. Using a log-normal model of glomerular pore size distribution, $r *(5 \%)$ and $r^{*}(1 \%)$, indices for the presence of large pores, were increased in the nephrotic patients. The fractional clearance of negatively charged dextran sulfate was significantly higher in all patient groups, indicating a loss of glomerular charge selectivity. Biopsy findings showed more prominent glomerular lesions in the nephrotic group compared with the moderately proteinuric group. We conclude that mild proteinuria late after renal transplantation is associated with a defect in glomerular charge selectivity. The development of nephrotic range proteinuria is associated also with a defect of glomerular size selectivity, which correlates with prominent glomerular pathology. (J. Clin. Invest. 1995. 96:22-29.) Key words: kidney glomerulus - proteinuria • nephrosis $\bullet$ permeability $\bullet$ graft rejection
\end{abstract}

\section{Introduction}

With an increasing number of renal transplantations performed, chronic allograft failure is becoming a common cause of terminal renal failure. It remains to be determined whether immunological and/or nonimmunological factors play the major role in the progression of this disease entity. Hypertension and proteinuria are among the clinical hallmarks of chronic allograft dysfunction $(1,2)$. However, the exact alterations of glomerular function and structure responsible for protein leakage in these patients are currently unknown.

In general, the transport of macromolecules (and thus pro-

Address correspondence to Gert Mayer, M.D., Department of Internal Medicine III, Division of Nephrology, University of Vienna, Währinger Gürtel 18-20, 1090 Vienna, Austria. Phone: 1-40400-4390; FAX: 140400-4392.

Received for publication 25 May 1994 and accepted in revised form 14 March 1995.

J. Clin. Invest.

(C) The American Society for Clinical Investigation, Inc.

0021-9738/95/07/0022/08 \$2.00

Volume 96, July 1995, 22-29 teins) through the glomerular filter is determined by their molecular size, charge, and shape (3). As endogenous proteins undergo a variable rate of tubular reabsorption they cannot be used directly to elucidate the characteristics of the glomerular filter. Therefore, tubular inert exogenous polymers are used for this purpose. The sieving coefficient theta $(\theta)$, the final urine to plasma concentration ratio of these markers, divided by the urine to plasma concentration of an ideal marker for glomerular filtration is equivalent to the Bowman's space to plasma concentration ratio. It is therefore the most direct measure of the intrinsic barrier properties of the glomerular capillary wall. Neutral dextrans of broad size distribution serve as markers for glomerular size selectivity (4). Negatively charged dextran sulfate on the contrary is being used to determine glomerular charge selectivity (5).

We applied these techniques to investigate glomerular permselective properties in patients after kidney transplantation with moderate and nephrotic range proteinuria in the late posttransplant period. Furthermore, patients after living related donor transplantation with moderate proteinuria, which never exhibited clinical evidence of (acute or chronic) rejection, and a group of normal, healthy controls were studied. In the nephrotic patients the fractional clearances of albumin and IgG (as further estimates of glomerular charge and size selectivity) were determined.

12 of the 16 nephrotic patients and 4 of the 10 moderately proteinuric patients underwent allograft biopsy within $4 \mathrm{wk}$ of the clearance studies. Biopsy cores were evaluated using the Banff classification of renal allograft rejection (6) to gain insight into the structural-functional relationship of allograft proteinuria.

\section{Methods}

\section{Subjects}

Group 1 consisted of 10 patients ( 3 male/7 female, mean age $52 \pm 5$ yr) with a 24-h urinary protein excretion below $1 \mathrm{~g} / \mathrm{d}$ (median proteinuria $0.37 \mathrm{~g} / \mathrm{d}$, range $0.20-0.79$ ); group 2 consisted of 16 nephrotic patients ( 10 male/ 6 female, mean age $51 \pm 3 \mathrm{yr})$ with proteinuria in excess of $3.5 \mathrm{~g} / \mathrm{d}(6.73 \mathrm{~g} / \mathrm{d}, 3.9-14.6)$ after cadaveric renal transplantation; and group 3 consisted of 8 patients $(5 \mathrm{male} / 3$ female, mean age $26 \pm 2 \mathrm{yr})$ with proteinuria below $0.6 \mathrm{~g} / \mathrm{d}(0.26 \mathrm{~g} / \mathrm{d}, 0.06-0.58)$ who received a living related donor transplant. As native kidney biopsy was performed only in a minority of patients, the diagnosis of the native kidney disease leading to chronic renal insufficiency was made mainly on clinical impressions with chronic glomerulonephritis being the most frequent cause in all groups $(\sim 50 \%)$, followed by polycystic kidney disease and chronic interstitial nephritis. One patient became uremic because of diabetic nephropathy. All patients had undergone binephrectomy or had only minimal residual function of their native kidneys (i.e., urinary output $<200 \mathrm{ml} /$ d) before transplantation. 12 healthy volunteers ( 7 male $/ 5$ female, mean age $27 \pm 2 \mathrm{yr}$, group 4 ) without any history of renal disease or hypertension and with a negative urinary dipstick test for albumin served as controls. 
Table I. Graft Function, 24-h Urinary Protein Excretion $\left(U_{P R O T} V\right)$ 6 mo before and at the Time of the Study and Time after Transplantation in the Three Patient Groups

\begin{tabular}{llll}
\hline & $\begin{array}{c}\text { Moderately } \\
\text { proteinuric } \\
\text { patients } \\
\text { (group 1) }\end{array}$ & $\begin{array}{c}\text { Nephrotic } \\
\text { patients } \\
\text { (group 2) }\end{array}$ & $\begin{array}{c}\text { Living } \\
\text { related donor } \\
\text { transplant } \\
\text { recipients } \\
\text { (group 3) }\end{array}$ \\
\hline $\begin{array}{c}\text { Serum creatinine } \\
\quad(\mu \text { mol/liter) }\end{array}$ & & & \\
-6 mo & $133 \pm 9$ & $178 \pm 12$ & $157 \pm 17$ \\
At study & $151 \pm 11^{*}$ & $208 \pm 15^{* \ddagger}$ & $157 \pm 17$ \\
$\begin{array}{c}\mathrm{U}_{\text {PRorV (g/d) }} \text {-6 mo } \\
\text { At study }\end{array}$ & $0.31 \pm 0.06$ & $5.10 \pm 1.10^{\ddagger}$ & $0.22 \pm 0.08$ \\
$\begin{array}{c}\text { Time after transplantation } \\
\text { (mo) }\end{array}$ & $0.30 \pm 0.05$ & $8.77 \pm 1.23^{* \ddagger}$ & $0.30 \pm 0.08$ \\
& $40 \pm 9$ & $58 \pm 9$ & $56 \pm 10$ \\
\hline
\end{tabular}

${ }^{\ddagger} P<0.05$ group 2 vs. groups 1 and $3 .{ }^{*} P<0.05$ at study vs. -6 mo. In the 6 mo preceeding the study, allograft function remained stable only in living related donor transplant recipients. Urinary protein excretion was progressive and higher in nephrotic patients when compared with all other groups.

All allograft recipients were in the late posttransplant period, and patients in group 1 and 2 had a slow deterioration of excretory allograft function during the 6 mo preceding the study, but all had serum creatinine values below $310 \mu \mathrm{mol} / \mathrm{liter}(3.5 \mathrm{mg} / \mathrm{dl})$. No acute rejection had to be treated for at least 6 mo before the permselective studies and there was no difference between the two cadaver transplant groups in the total number of acute rejection episodes during their posttransplant course. The patients with the living donor transplants never exhibited clinical evidence of rejection. All patients were in the late posttransplant period, although group 1 patients were studied slightly earlier after transplantation. Details of the clinical course of the patients are presented in Table I.

$12 / 16$ patients in group 2 and 4/10 patients in group 1 underwent an allograft biopsy within $4 \mathrm{wk}$ of the study, and the biopsy core was scored according to the Banff working classification for renal allograft rejection (6). In six nephrotic patients, material was available for electron microscopy.

Basic immunosuppressive therapy was similar in the three groups and can be seen in Table II. Cyclosporin A through levels were measured immediately before the clearance studies (i.e., $12 \mathrm{~h}$ after the last dose). To control blood pressure, 8 out of the 10 patients in group 1, 14 of the 16 patients in group 2 , and 5 of the 8 living related donor transplant recipients were on antihypertensive therapy.

One transplant patient refused to participate in the dextran sulfate studies and in another a technical failure occurred during the gel permeation chromatography. Both patients were in the nephrotic group. Urinary IgG could only be measured in 14 out of 16 patients.

\section{Functional studies}

On the day of the studies the patients and controls were told not to take their antihypertensive medication. Before the clearance studies, subjects were told to void completely and an oral water load of $10 \mathrm{ml} / \mathrm{kg}$ body wt was given to ensure a high urine output. Afterwards the subjects received a bolus of Dextran 1000 (Promit ${ }^{\oplus}$; Kabi Pharmacia, Uppsala, Sweden ) $(20 \mathrm{ml}, 0.15 \mathrm{~g} / \mathrm{ml})$, followed by a 30 -min infusion of a $1: 5$ Dextran 40/Dextran 70 mixture at a total dose of $130 \mathrm{mg}$ Dextran $/ \mathrm{kg}$ body wt. Dextran 40 and Dextran 70 (Ebewe, Unterach, Austria) are clinical preparations of polydisperse dextrans with mean molecular weights of 40,000 and 70,000 , respectively. Patients or controls with a
Table II. Basic Immunosuppression in the Three Transplant Patient Groups

\begin{tabular}{|c|c|c|c|}
\hline & $\begin{array}{c}\text { Moderately } \\
\text { proteinuric } \\
\text { patients } \\
\text { (group 1) }\end{array}$ & $\begin{array}{l}\text { Nephrotic } \\
\text { patients } \\
\text { (group 2) }\end{array}$ & $\begin{array}{l}\text { Living } \\
\text { related donor } \\
\text { transplant } \\
\text { recipients } \\
\text { (group 3) }\end{array}$ \\
\hline Prednisolon (mg/d) & $11 \pm 3$ & $11 \pm 1$ & $8 \pm 1$ \\
\hline Azathioprin (mg/d) & $67 \pm 8$ & $64 \pm 7$ & $82 \pm 7$ \\
\hline $\begin{array}{l}\text { Cyclosporin A through level } \\
\text { (ng/ml) }\end{array}$ & $106 \pm 5$ & $93 \pm 5$ & $94 \pm 11$ \\
\hline
\end{tabular}

Immunosuppressive therapy was identical in all patient groups.

history of penicillin allergy were excluded from the study to eliminate risk factors for dextran allergy and no adverse events occurred during the study. We used this mixture and not the commonly used Dextran 40 preparation alone in an effort to extend the sieving curve to higher radii. Nonetheless, we were not able to measure the urinary concentration of dextrans > $60 \AA$. An iothalamate (Conray $60^{\circ}$; Cl Pharma, Linz, Austria) and para-aminohippuric acid (PAH) ${ }^{1}$ bolus (Nephrotest ${ }^{\star}$; BAG, Lich, Germany) followed by a continuous infusion was administered immediately after the Dextran 1000 infusion. Bolus amount and infusion rate were adjusted to the estimated distribution volume and glomerular filtration rate in order to obtain constant iothalamate plasma levels of $\sim 1.5 \mathrm{mg} / \mathrm{dl}$ and PAH plasma levels of $\sim 2 \mathrm{mg} / \mathrm{dl}$.

A dextran sulfate preparation (Ueno Fine Chemicals, Osaka, Japan) was tritiated (New England Nuclear Corp., Boston, MA), as a dose in the toxic range of the unlabeled preparation would have to be infused to achieve plasma concentrations within the assayable range. Details on the preparation used are given elsewhere (7). The final preparation was checked for free radioactivity by gel permeation chromatography (see below). $300 \mu \mathrm{Ci}$ was infused as a bolus within $5 \mathrm{~min}$ after the neutral dextran infusion was finished.

After an equilibration period of $90 \mathrm{~min}$, two clearance periods (30 min each) were performed. Blood was drawn at the beginning and end of each period and analysis was done on pooled plasma. Urine was collected throughout the clearance periods and urinary fluid losses were replaced immediately by oral tap water.

\section{Analytical methods}

Analysis of neutral dextran. Neutral dextran size separation of plasma and urine samples was performed using a size exclusion HPLC (Jasco International Co. Ltd., Tokyo, Japan) which consisted of a guard column (Ultrahydrogel Guard Column) and two serially arranged columns (UItrahydrogel 250 and Ultrahydrogel 500; Waters Chromatography, Milford, MA). The concentration of the dextran fractions was measured using an on-line refractive index detector. The mobile phase was a 0.1 M phosphate buffer, $\mathrm{pH}$ 6.5. The column calibration standards, which were a set of dextrans of narrow size distribution with molecular weights determined by light scattering, were obtained from Pharmacia Fine Chemicals (Uppsala, Sweden). Plasma and urine sample preparation was performed as described in detail elsewhere (8).

We measured the clearance for neutral dextrans over a size range from 30 to $60 \AA$. Below $30 \AA$ the accuracy was limited by an interfering

1. Abbreviations used in this paper: FSGS, focal and segmental glomerulosclerosis; $\triangle \mathrm{p}$, effective filtration pressure; $\mathrm{PAH}$, para-aminohippuric acid. 
plasma protein peak. Above $60 \AA$ determination of dextrans in the urine was not possible due to very low concentrations. The recovery of neutral dextrans from urine was $98 \pm 1 \%$ at $30 \AA$ and declined to $92 \pm 1.5 \%$ at $60 \AA$, the recovery from plasma at $30 \AA$ was $93 \pm 0.3 \%$ and declined to $84 \pm 1 \%$ at $60 \AA$. The interassay coefficient of variation for the neutral dextran analysis was $3 \%$ at $30 \AA$ and $6 \%$ at $60 \AA$.

Analysis of dextran sulfate. The concentration of tritiated dextran sulfate in urine and plasma was measured by liquid scintillation counting (Beckman Instruments, Inc., Fullerton, CA). As reported previously, dextran sulfate is significantly bound to plasma proteins $(7,8)$. Separation of bound and free dextran sulfate was performed using gel permeation chromatography. Each individual plasma and urine sample was put on top of a $1.5 \times 30 \mathrm{~cm}$ Econo-column filled with a P-60 gel (BioRad Labs, Richmond, CA). PBS was used as rinsing solution and 23 fractions, $3 \mathrm{ml}$ each, were collected. One peak eluted in fractions $5-7$, another in fractions 13-16; the recovery of total radioactivity in these two peaks for all samples analyzed was $95 \pm 2 \%$. The latter peak was identified as dextran sulfate using gel permeation chromatography of a cold preparation of the compound. The fractions obtained there were analyzed on a size exclusion HPLC with an on-line refractive index detector. The material detected eluted at the same time as unfractionated cold dextran sulfate analyzed by HPLC immediately. When excess cold dextran sulfate was added to plasma samples containing tritiated material and gel permeation was performed afterwards, only a single peak of tritiated dextran sulfate eluted. It was concluded that the tritiated dextran sulfate was replaced by unlabeled dextran sulfate. As no size standard preparations are available for dextran sulfate, we indirectly estimated the size of the fractions by analyzing them on a size exclusion HPLC system calibrated with neutral dextrans. The estimated size of the second (free) peak was 18-20 ̊ and therefore corresponded well with the manufacturer's statements.

Only the unbound plasma dextran sulfate concentration was used to calculate the dextran sulfate clearance. Using this procedure, the fraction of non-protein-bound dextran sulfate was significantly lower in nephrotic patients $(64 \pm 1 \%$ in group $2,76 \pm 1 \%$ in group $1,71 \pm 1 \%$ in group 3 , and $74 \pm 1 \%$ in group $4 ; P<0.05$ group 2 vs. group 1 , group 3 and group 4). Dextran sulfate is used to remove plasma lipoproteins in LDL apheresis (9). It might therefore be speculated that in patients with hyperlipoproteinemia due to nephrosis more of the compound is protein bound. When urine samples were analyzed by gel chromatography, even in nephrotic patients a very small fraction $(<2 \%$ of total radioactivity in each case) eluted with the first peak. Therefore, the total radioactivity of the urine samples was used to calculate the fractional dextran sulfate clearance values.

Analysis of PAH and iothalamate. Analysis of PAH and iothalamate was performed using a reversed phase HPLC system (Jasco International Co. Ltd.) consisting of a guard column (Ultrasphere Octyl) and a main column (Ultrasphere ODS; Beckman Instruments, Inc.) as described by Morelli et al. (10). The recovery of PAH in plasma was $92 \pm 2 \%$ and in urine $90 \pm 3 \%$, for iothalamate the corresponding values were $93 \pm 2 \%$ and $92 \pm 2 \%$. The interassay coefficient of variation for PAH measured in plasma and urine samples was 7 and $9 \%$ and for iothalamate 5 and 3\%, respectively. PAH clearance values were used as a marker of glomerular plasma flow. As the extraction of PAH is incomplete in advanced renal failure, an extraction rate of 0.7 was assumed in patients with a GFR $<40 \mathrm{ml} / \mathrm{min}(11)$.

Other analyses. Blood pressure was measured by the Riva Rocci method after the patients had been resting for $5 \mathrm{~min}$. Cyclosporin A through levels were determined using a specific monoclonal antibody (Cyclotrac ${ }^{\circledR}$; Incstar, Stillwater, MN). Protein concentrations were determined by a colorimetric assay (Protein Assay ${ }^{\circledR} ;$ Bio-Rad Labs). Concentrations of albumin and IgG in serum and urine were measured by radial immunodiffusion (lower detection limit $50 \mu \mathrm{g} / \mathrm{ml}$ for plasma and $20 \mu \mathrm{g} / \mathrm{ml}$ for urine). If the concentration of either protein fell below the detection limit, a sensitive enzyme-linked immunosorbent assay (ELISA) with a lower detection limit of $3 \mathrm{ng} / \mathrm{ml}$ was used.

\section{Calculations}

The fractional clearance theta $(\theta)$ of any marker was calculated using the equation:

Theta marker $\left(\theta_{\mathrm{m}}\right)=\frac{\text { clearance marker }}{\text { clearance iothalamate. }}$

The size selective properties of the glomerular filter were analyzed using two mathematical models. One is based on the assumption that the major portion of the capillary wall is perforated by cylindrical pores of identical radius. Furthermore, there exists an additional parallel "shunt pathway" which does not discriminate on the basis of dextran size and through which a small fraction of the filtrate volume passes. The second model assumes that the radii of the pores follow a lognormal distribution. Both models were described extensively by Deen and co-workers (12). It turned out that the log-normal distribution of pore radii best simulated the data obtained in vivo. Output variables of this model are the mean radius of the pores and the standard deviation of the mean radius ( $\mu$ and $\mathrm{s}$ ) as well as $\mathrm{r} *(1 \%)$ and $\mathrm{r} *(5 \%)$. These latter two parameters determine the radius of the pores above which 1 and $5 \%$ of the glomerular filtrate are formed. In summary, these parameters characterize the presence of large pores within the filter. Both models require the effective filtration pressure $(\Delta p)$ as an input variable. As this pressure cannot be measured in humans, several assumptions have been made on $\Delta p$ in our study (variation of $\Delta p$ between 35 and $50 \mathrm{mmHg}$ in transplant patients and 40 and $45 \mathrm{mmHg}$ in healthy controls). These values for filtration pressure seem to be an acceptable assumption according to values obtained with servonulling techniques in experimental rodents. It should furthermore be pointed out that the variations in $\Delta \mathrm{p}$ mainly alter the theoretical sieving of smaller dextran molecules and therefore do not influence the shunt parameter or $\mathrm{r}$ * values.

The ultrafiltration coefficient $K_{\mathrm{f}}$ was then calculated using different ultrafiltration pressure values.

\section{Statistics}

All results are expressed as mean \pm SEM, except protein excretion, which, because of its non-Gaussian distribution, is given as median and range. Two tailed Student's $t$ test for paired data and non-parametric Mann-Whitney test were used to assess differences between the two time points ( 6 mo before and at the time of the study) within one group. Data on all four groups were analyzed using ANOVA and Fisher's exact test. A $P$ value $<0.05$ was considered statistically significant.

The study was approved by the local human subject committee and a written informed consent was obtained from every patient before the study.

\section{Results}

Excretory kidney function, renal plasma flow, and systemic blood pressure. Values for mean arterial blood pressure, iothalamate, and PAH clearances are given in Table III. GFR and PAH clearance values in the controls are expressed per single kidney to permit comparison. All transplant patient groups had comparable, although when compared with healthy individuals, reduced GFR values. However, only in nephrotic patients did this difference reach statistical significance. Mean arterial blood pressure was elevated in transplant patients, although again only nephrotic patients had significant hypertension.

Neutral dextran studies and theoretical analysis of the pore size distribution. The fractional clearance values for neutral dextrans in the nonnephrotic cadaver and living related donor transplant recipients were similar to, but uniformly elevated above, the ones obtained in healthy controls. On the contrary, the fractional clearance for neutral dextrans $>54 \AA$ was sig- 
Table III. Mean Arterial Blood Pressure (MAP), GFR, and PAH Clearance Values in the Three Transplant Patient Groups and in Healthy Controls

\begin{tabular}{|c|c|c|c|c|}
\hline & $\begin{array}{c}\text { Moderately } \\
\text { proteinuric } \\
\text { patients } \\
\text { (group 1) }\end{array}$ & $\begin{array}{l}\text { Nephrotic } \\
\text { patients } \\
\text { (group 2) }\end{array}$ & $\begin{array}{l}\text { Living } \\
\text { related donor } \\
\text { transplant } \\
\text { recipients } \\
\text { (group 3) }\end{array}$ & $\begin{array}{l}\text { Healthy } \\
\text { controls } \\
\text { (group 4) }\end{array}$ \\
\hline MAP (mmHg) & $108 \pm 4$ & $111 \pm 3$ & $106 \pm 5$ & $100 \pm 2 *$ \\
\hline $\mathrm{GFR}(\mathrm{ml} / \mathrm{min})$ & $47 \pm 6$ & $40 \pm 7$ & $48 \pm 7$ & $63 \pm 8^{* \ddagger}$ \\
\hline PAH clearance $(\mathrm{ml} / \mathrm{min})$ & $259 \pm 25$ & $255 \pm 75$ & $293 \pm 47$ & $338 \pm 74^{\ddagger}$ \\
\hline
\end{tabular}

${ }^{*} P<0.05$ group 4 vs. group $2 .{ }^{\ddagger}$ Value per one kidney. Blood pressure was comparable in the three transplant patient groups, although only nephrotic patients had significant hypertension when compared with normal controls. GFR clearance values were significantly lower in nephrotic transplant recipients when compared with healthy controls, but no difference was found between the groups.

nificantly higher in transplant recipients with nephrotic range proteinuria than in any other group, demonstrating a defect in glomerular size selectivity (Fig. 1).

Table IV gives values for membrane parameters obtained using the log-normal model of Deen et al. (12). $\Delta p$ in normal control subjects was set at 40 and $45 \mathrm{mmHg}$ and in recipients was allowed to range from 35 to $50 \mathrm{mmHg}$. The lower value in each group was chosen according to the calculated efferent arteriolar oncotic pressure, which averaged $39 \mathrm{mmHg}$ in controls and $33 \mathrm{mmHg}$ in transplant recipients. Calculated values for membrane pore parameters indicated that pore size distribution was significantly altered in group 2 recipients with heavy proteinuria. In particular, values for $r^{*}(5 \%)$ and $r *(1 \%)$ in this group exceeded those of the other groups, irrespective of the assumptions made regarding glomerular transcapillary pressure. As described by Remuzzi et al. (13), these two parameters determine the radius of the pores above which 1 and $5 \%$ of the glomerular filtrate are formed. Therefore, the finding of increased values for $\mathrm{r}^{*}(5 \%)$ and $\mathrm{r}^{*}(1 \%)$ irrespective of assumed variation in $\Delta p$ indicates that the prevalence of large membrane pores was increased in group 2. Furthermore, the pore size distribution is wider in the nephrotic patient group. Table IV also gives values for the whole kidney ultrafiltration $K_{\mathrm{f}}$ (for the healthy control group $K_{\mathrm{f}}$ is given per single kidney). As revealed by Table IV, calculated values for $K_{\mathrm{f}}$ depend heavily on assumed values for $\Delta p$. For most assumed values of $\Delta p$, whole kidney $K_{\mathrm{f}}$ was reduced in the recipient groups. This reflects the reduction of GFR values in these groups to less than the control single kidney value. Of note, values for $K_{\mathrm{f}}$ were lowest in group 2 patients who exhibited the lowest mean values for GFR despite having a reduction in plasma protein concentration and calculated plasma oncotic pressure.

Dextran sulfate clearance studies. Results of clearance studies using anionic dextran sulfate as a marker for glomerular charge selectivity are shown in Fig. 2. The fractional clearance of dextran sulfate was significantly lower in normal control subjects when compared with all transplanted patients. There was, however, no difference between the three patient groups (fractional clearance of negatively charged dextran sulfate in healthy volunteers $0.57 \pm 0.04,0.79 \pm 0.06$ in the patients with moderate proteinuria, $0.76 \pm 0.05$ in nephrotic patients, and $0.77 \pm 0.06$ in living related donor transplant recipients). The fractional clearance of neutral dextrans of the size of our dextran sulfate preparation has been shown to be close to 1 (7). Therefore, a value of 0.57 demonstrates intact charge selectivity in healthy patients, whereas values of 0.8 demonstrate a loss of glomerular charge selectivity.

Fractional clearance of albumin and IgG in nephrotic patients. To further characterize the defect that leads to increasing proteinuria in allograft recipients, we determined the fractional clearance values of IgG and albumin in group 2 patients. The Einstein-Stoke's radius of albumin is $36 \AA$, the radius of IgG is estimated to be $55 \AA$. Although a pore radius of $50 \AA$, as estimated by neutral dextran sieving, probably overestimates true pore size, the passage of albumin through the glomerular filter should be hindered mostly by its negative molecular charge, whereas IgG can serve as an additional marker for glomerular size selectivity. As can be seen from Fig. 3, the frac-

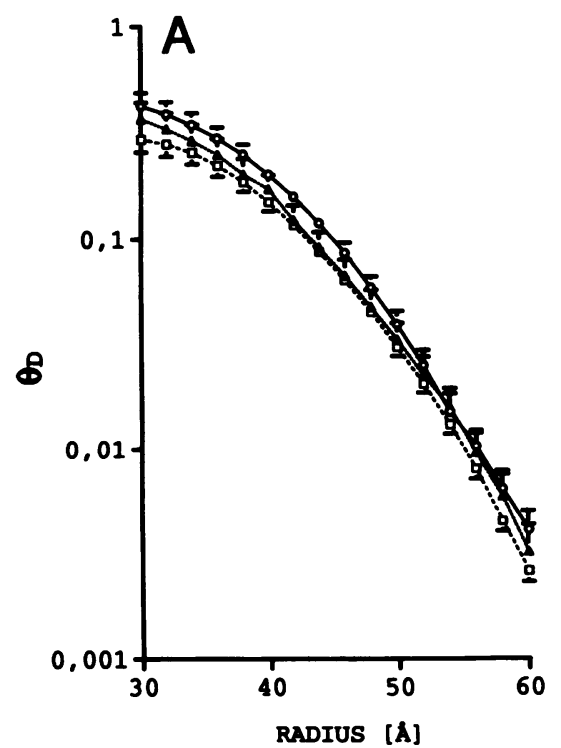

RADIUS [A]

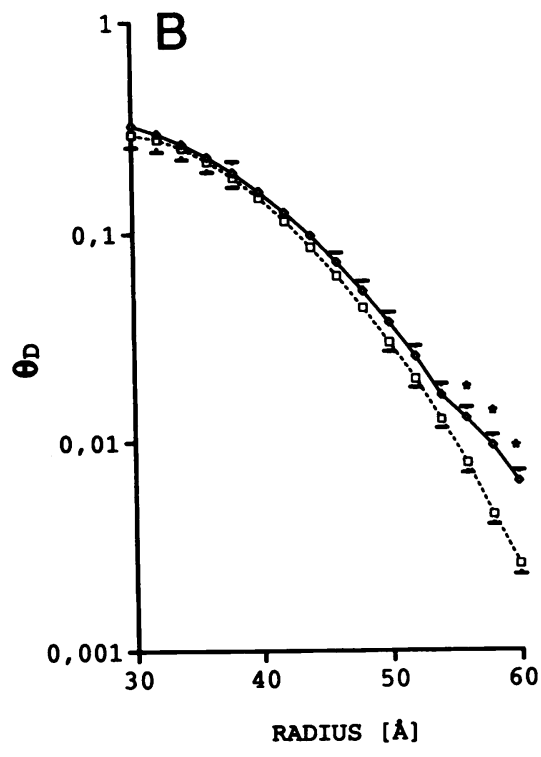

Figure 1. Fractional clearance of neutral dextrans $\left(\theta_{\mathrm{D}}\right)$ of broad size distribution as a function of molecular radius $(\AA)$. $(A)$ The fractional clearance of neutral dextrans of cadaver (group 1, circles) and living related donor transplant recipients (group 3, triangles) with nonnephrotic range proteinuria was uniformly elevated but similar to that observed in controls (group 4, squares), demonstrating an intact glomerular size selectivity. ( $B$ ) Cadaver renal transplant recipients with nephrotic range proteinuria (group 2 , diamonds) exhibit a defect in glomerular size selectivity as evident by significantly elevated fractional clearance values for neutral dextrans $>54 \AA$ A when compared with healthy controls (group 4, squares). $* P<0.05$ group 4 vs. group 2 . 
Table IV. Calculated Glomerular Pore Parameters Obtained Using a Log-Normal Model and Various Filtration Pressures

\begin{tabular}{|c|c|c|c|c|c|c|}
\hline & $\mu$ & s & $\mathrm{r}^{*}(1 \%)$ & $\mathrm{r}^{*}(5 \%)$ & $K_{\mathrm{f}}$ & $\Delta \mathrm{p}$ \\
\hline & $\dot{A}$ & $\dot{A}$ & $\dot{A}$ & $\AA$ & $\mathrm{ml} / \mathrm{min} / \mathrm{mmHg}$ & $\mathrm{mmHg}$ \\
\hline \multirow[t]{4}{*}{ Moderately proteinuric patients (group 1) } & 54.17 & 1.13 & 76.6 & 70.4 & 10.76 & 35 \\
\hline & 58.63 & 1.09 & 72.4 & 68.5 & 4.74 & 40 \\
\hline & 59.33 & 1.08 & 71.5 & 68.1 & 3.12 & 45 \\
\hline & 59.55 & 1.07 & 71.2 & 68.0 & 2.33 & 50 \\
\hline \multirow[t]{4}{*}{ Nephrotic patients (group 2) } & 51.65 & 1.17 & 80.9 & 72.9 & 3.18 & 35 \\
\hline & 53.05 & 1.15 & 80.0 & 72.6 & 2.27 & 40 \\
\hline & 53.66 & 1.15 & 79.6 & 72.5 & 1.77 & 45 \\
\hline & 53.96 & 1.14 & 79.3 & 72.4 & 1.45 & 50 \\
\hline \multirow[t]{4}{*}{ Living related donor transplant recipients (group 3) } & 49.54 & 1.17 & 78.3 & 70.4 & 8.35 & 35 \\
\hline & 54.54 & 1.12 & 74.6 & 69.1 & 4.36 & 40 \\
\hline & 55.85 & 1.11 & 73.4 & 68.6 & 2.98 & 45 \\
\hline & 56.34 & 1.10 & 72.9 & 68.3 & 2.27 & 50 \\
\hline \multirow[t]{2}{*}{ Healthy controls (group 4) } & 50.23 & 1.15 & 75.5 & 68.6 & $8.92 *$ & 40 \\
\hline & 53.82 & 1.12 & 73.3 & 67.9 & $5.26 *$ & 45 \\
\hline
\end{tabular}

$\mu$, mean pore radius. s, standard deviation of mean pore radius. $\mathrm{r}^{*}(1 \%$ and $5 \%)$, radius of pores, above which 1 and $5 \%$ of the glomerular filtrate is formed. $\Delta \mathrm{p}$, filtration pressure. $K_{\mathrm{f}}$, glomerular ultrafiltration coefficient. * Value per one kidney. Calculated values for glomerular pore parameters indicate that the pore size distribution was altered in group 2 . In particular, values for $\mathrm{s}, \mathrm{r}^{*}(5 \%)$, and $\mathrm{r}^{*}(1 \%)$ in this group exceeded those in the other groups, irrespective of assumed variation in $\Delta \mathrm{p}$, indicating the increase of large membrane pores in nephrotic patients. For all assumed values of $\Delta \mathrm{p}, K_{\mathrm{f}}$ was reduced in the recipient groups, reflecting the reduction of GFR values in these groups to less than the control single kidney value.

tional clearance of albumin always exceeded the fractional clearance of IgG. However, as proteinuria increased, the regression line approached the line of identity (i.e., $\theta_{\mathrm{IgG}}$ increased more rapidly, as did $\left.\theta_{\text {Albumin }}\right)$, indicating a more pronounced defect of glomerular size selectivity with increasing proteinuria.

Histopathology of the transplant biopsies. Most biopsies showed a rather complex pattern of chronic lesions. In all patients a moderate to severe, mostly striped, and sometimes diffuse interstitial fibrosis could be observed. This was, together with a hyalinotic arteriolopathy, attributed to chronic $\mathrm{Cy}$ closporin A toxicity. The main difference between the two groups was found in glomerular pathology, as all moderately proteinuric patients showed only minor, nonspecific glomerular lesions. In nephrotic patients, glomerular pathology in light mi-

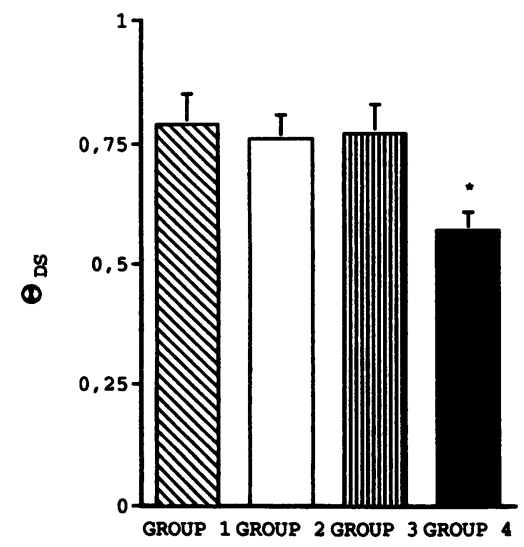

Figure 2. Fractional clearance of dextran sulfate $\left(\theta_{\mathrm{DS}}\right)$ of narrow size distribution. Patients after kidney transplantation exhibit a defect in glomerular charge selectivity as evident by an elevated fractional clearance of negatively charged dextran sulfate when compared with healthy controls (moderately proteinuric patients, group 1, hatched bar; nephrotic patients, group 2, open bar; living re-

lated donor transplant recipients, group 3, striped bar; healthy controls, group 4 , closed bar). $* P<0.05$ group 4 vs. all other groups. croscopy was evident as marked transplant glomerulopathy, glomerular scaring, and signs of focal and segmental glomerulosclerosis (FSGS; focal and segmental or global sclerosis and obsolescence of the glomerular tuft, swollen or vacuolated, sometimes protein loaded podocytes and deposition of hyaline material in sclerotic areas). In eight of the nephrotic patients the glomeruli showed changes typical for transplant glomerulo-

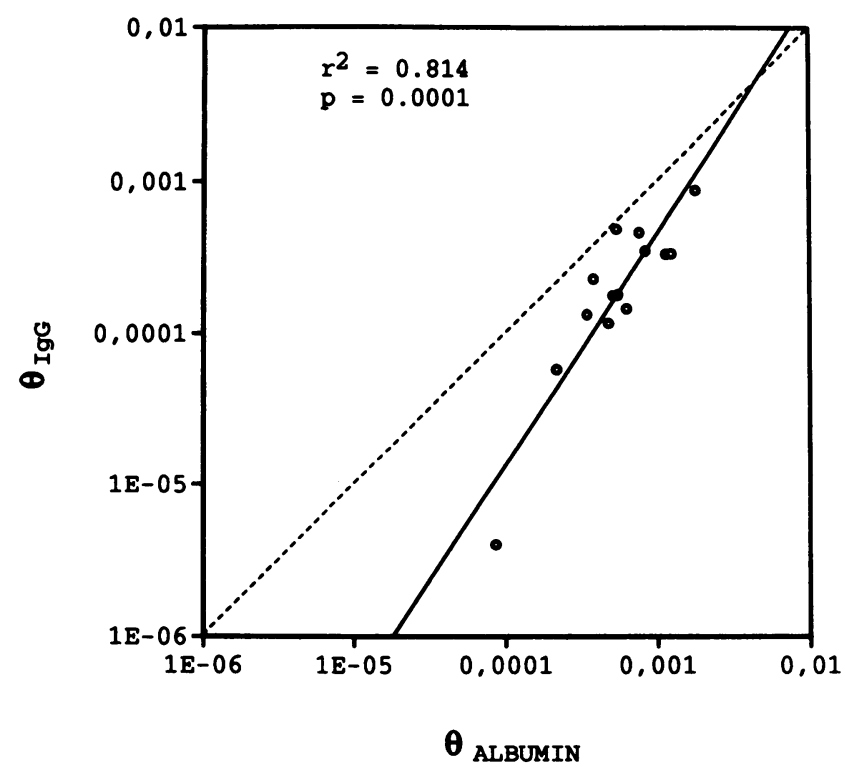

Figure 3. Fractional clearance of albumin $\left(\theta_{\mathrm{ALBUMIN}}\right)$ and $\mathrm{IgG}\left(\theta_{\mathrm{IgG}}\right)$ in nephrotic renal transplant patients. As proteinuria increases, the regression line approaches the line of identity, indicating an increasingly impaired glomerular size selectivity. 


\begin{tabular}{|c|c|c|c|c|c|c|}
\hline & \multicolumn{3}{|c|}{ Moderately proteinuric patients (group 1) } & \multicolumn{3}{|c|}{ Nephrotic patients (group 2) } \\
\hline & MEAN (ALL) & $n(\mathrm{POS})$ & MEAN (POS) & MEAN (ALL) & $n$ (POS) & MEAN (POS) \\
\hline & & $n=4$ & & & $n=12$ & \\
\hline \multicolumn{7}{|l|}{ Light microscopy } \\
\hline \multicolumn{7}{|l|}{ Glomerular lesions } \\
\hline TX-glomerulopathy & 0 & 0 & 0 & 1.3 & 8 & 1.9 \\
\hline \multicolumn{7}{|l|}{ Tubulointerstitial lesions } \\
\hline Fibrosis (and imflammation) & 1.5 & 4 & 1.8 & 2.1 & 12 & 2.1 \\
\hline Tubular atrophy & 1.3 & 3 & 1.7 & 1.8 & 12 & 1.8 \\
\hline \multicolumn{7}{|l|}{ Vascular lesions } \\
\hline Arteriolar hyalinosis & 1.3 & 2 & 1.5 & 1 & 8 & 1.5 \\
\hline Fibrous intimal thickening & 1.8 & 4 & 1.8 & 1.4 & 11 & 1.5 \\
\hline \multicolumn{7}{|l|}{ Others } \\
\hline Scarred glomeruli & 0 & 0 & 0 & 1.1 & 9 & 1.4 \\
\hline \multirow[t]{2}{*}{ FSGS } & 0 & 0 & 0 & 1.3 & 9 & 1.8 \\
\hline & & $n=0$ & & & $n=6$ & \\
\hline \multicolumn{7}{|l|}{ Electron microscopy } \\
\hline Foot process fusion & & & & 2.2 & 6 & 2.2 \\
\hline Electron dense deposits & & & & 0.3 & 2 & 1 \\
\hline
\end{tabular}

Evaluation of morphological criteria for chronic transplant lesions in light microscopy was done according to the Banff classification (6). The lesions were graded 0-3: $(0=$ absent, $1=$ slight, $2=$ moderate, and $3=$ severe $)$. For electron microscopy the same grading steps were applied. The score for the estimated extent of foot process fusion was: $0=9 \%, 1=10-29 \%, 2=30-69 \%, 3=70 \%$. MEAN (ALL), mean value of scores including all patients of the group; $n$ (POS), number of patients exhibiting a given lesion (thus scoring was at least 1); MEAN (POS), mean value of scores including only positive patients. The major difference between the two groups was found in glomerular pathology, which was present in light microscopy exclusively in nephrotic patients. These patients also exhibited prominent foot process fusion in electron microscopy.

pathy (basement membrane doubling and thickening). Transplant glomerulopathy was accompanied in all cases with intimal fibrosis of the arterioles. In nine patients a sometimes very prominent glomerular lesion was FSGS. The term FSGS was used as a description of morphological pattern rather than as an etiopathogenetic entity. It occurred either in association with other glomerular lesions or was the main pathologic change in glomeruli. It is unlikely that the FSGS present in our patients was recurrence of disease (although exact histological diagnosis of native kidney disease was not available in most patients), as slowly increasing proteinuria developed late after transplantation. In recurrent primary FSGS, nephrotic range proteinuria usually develops early after engraftment (14).

Electron microscopy was available in 6 out of the 12 nephrotic patients and showed a widespread patchy or diffuse fusion and flattening of the podocytic foot processes. Podocyte detachment from the glomerular basement membrane, a finding often described in proteinuric experimental renal disease, was also observed in our patient population. However, the frequency of this alteration was very low. The results of the light and electron microscopic evaluations are summarized in Table V.

\section{Discussion}

The main aim of this study was to characterize the defect in glomerular filter function that leads to proteinuria in renal allograft recipients late after transplantation. Several determinants of glomerular permselectivity (i.e., the capacity of the normal glomerulus to hinder the passage of macromolecules from the blood compartment to Bowman's space) have been described, the most important being glomerular size and charge selectivity. Large and/or negatively charged molecules are less readily filtered than small and/or cationic molecules (3-5). In this study we used ideal markers for glomerular charge and size selectivity, as both neutral dextrans as well as dextran sulfate (in contrast to proteins) have been shown to be neither reabsorbed nor secreted by the renal tubular system $(4,15)$. After correction for water reabsorption, the concentration of these macromolecules in the final urine represents the concentration in Bowman's space.

Dextran sulfate, the marker for glomerular charge selectivity in our study, has been used mostly in animal studies $(5,15)$. Recently it has been demonstrated that dextran sulfate is protein bound in a significant manner and therefore the technique of calculating fractional clearance values has been modified accordingly $(7,8)$. Using these modifications, Guasch et al. (7) reported recently that in patients with membranous nephropathy fractional dextran sulfate clearance values were increased when compared with normal controls. This finding demonstrates a defect in glomerular charge selectivity in these patients. Even though the technique of separating protein bound from unbound dextran sulfate was slightly different in their study, our results are remarkably similar. Normal controls demonstrate a sieving coefficient of dextran sulfate of 0.6 , indicating a preserved glomerular charge selectivity as the fractional clearance for neutral dextran of that size is $\sim 1$ (7). Transplant recipients with pro- 
teinuria have significantly higher fractional clearance of dextran sulfate $(0.8)$. The same value is obtained in patients with moderate proteinuria irrespective of the origin of the transplant (cadaver or living related donation) and nephrotic range proteinuria, suggesting that the defect in glomerular charge selectivity is the common alteration of glomerular permselectivity that leads to proteinuria after transplantation. The fractional clearance of large dextrans was increased in nephrotic transplant recipients as compared with all other groups. Theoretical analysis of the dextran sieving data using the log-normal model revealed that this change reflected an increase in the prevalence of large pores in the glomerular membrane. As in previous studies of heavy proteinuria, this change was accompanied by a reduction in GFR despite a reduction in plasma oncotic pressure, indicating a reduction in $K_{\mathrm{f}}$ associated with severe injury to the glomerular capillary wall. In contrast to the findings in group 2 , dextran sieving curves were only slightly elevated across the size range studied in recipient groups 1 and 3 . The slight elevation of the sieving curve in these groups is consistent with the assumption of a decrease in $\Delta \mathrm{p}$ mediated by cyclosporine (4). It should be emphasized, however, that the conclusions of this study regarding charge and size selectivity in transplant recipients are not dependent on particular assumptions regarding glomerular pressure. In summary, in renal transplant recipients mild proteinuria is associated with a defect in glomerular charge selectivity. The development of nephrotic range proteinuria is associated also with a defect of glomerular size selectivity.

As demonstrated by our histopathological findings, the main structural correlate to the defect in glomerular size selectivity is the development of glomerular pathology, as the indices for vascular and interstitial pathology are similar in the nephrotic and moderately proteinuric cadaver transplant recipients. Interestingly, on an electron microscopy level, detachment of the glomerular epithelial cells from the basement membrane was a very infrequent finding. This alteration has been shown to correlate with proteinuria in experimental renal disease (16). Of interest however, Miller et al. (17) have shown that glomerular hypertrophy, induced by four-fifths renal ablation, increases the area of epithelial cell detachment in adriamycin nephrosis. On the contrary, Lafayette and co-workers (18) reported that Cyclosporin A treatment reduces glomerular volume in rats. Therefore, besides the possibility of a sampling error, preserved podocyte adhesion to the basement membrane in our patients might be due to less prominent glomerular hypertrophy due to treatment with Cyclosporin A.

The nephrotic transplant patients had been transplanted for a slightly longer time when compared with the nonnephrotic cadaver transplant recipients. We therefore retrospectively evaluated proteinuria in the nephrotic patients 18 mo before the study to match the time after transplant between the two groups. At that time point proteinuria was $1.25 \mathrm{~g} / \mathrm{d}$, a value quite similar to that observed in our moderately proteinuric groups at the time of the study. This also is in line with the assumption that proteinuria in these patients develops by an initial defect in glomerular charge selectivity. Later on, as heavy proteinuria develops, glomerular size selectivity becomes increasingly impaired. Even in nephrotic patients, this sequence of events is prolonged as shown by our data on the relationship between the fractional albumin and IgG clearance.

The results we obtained in our transplant patients are similar to that obtained by others in native kidney disease. In patients with diabetic nephropathy, Deckert et al. (19) recently reported a similar sequence in the evolution of proteinuria. Using an IgG/IgG4 selectivity index as a marker for glomerular charge selectivity, a defect was evident in patients with albuminuria in the range of $100-300 \mathrm{mg} / 24 \mathrm{~h}$. Neutral dextran sieving was only altered in patients with albuminuria of $>1,500 \mathrm{mg} / \mathrm{d}$ (19). Scandling and co-workers (20) found a similar relationship between the fractional clearance of albumin and IgG in patients with various nephrotic native kidney diseases.

With the increasing number of transplants performed, chronic allograft dysfunction is becoming a major problem in clinical nephrology. If proteinuria in patients late after kidney transplantation is caused by a comparable defect as nephrosis in native kidney disease, similar treatment options might be available. In native kidney disease, blockade of the renin angiotensin system has been shown to effectively lower proteinuria $(21,22)$. Using neutral dextran sieving analysis, several authors were able to demonstrate a beneficial effect of angiotensin converting enzyme blockade on glomerular size selectivity in these patients $(10,13,23,24)$. Accordingly, Traindl et al. (25) reported a beneficial effect of angiotensin converting enzyme inhibitor treatment on proteinuria in renal transplant recipients.

Furthermore, Remuzzi et al. (26) suggested recently that proteinuria per se might lead to a progressive decline in renal excretory function. It remains to be determined, however, whether a reduction in proteinuria in renal transplant recipients might slow the progression of chronic transplant failure.

\section{Acknowledgments}

This study was supported by the Österreichischer Fond zur Förderung der Wissenschaftlichen Forschung, grant P 9002 MED.

\section{References}

1. Cheigh, J. S., R. H. Haschemeyer, J. C. L. Wang, R. R. Riggio, L. Tapia, K. H. Stenzel, and A. L. Rubin. 1989. Hypertension in kidney transplant recipients: effect on long-term renal allograft survival. Am. J. Hyperten. 2:341-348.

2. Harlan, W. R., K. R. Holden, G. M. Williams, and D. M. Hume. 1967 Proteinuria and nephrotic syndrome associated with chronic rejection of kidney transplants. N. Engl. J. Med. 277:769-776.

3. Deen, W. M., C. R. Bridges, and B. M. Brenner. 1983. Biophysical basis of glomerular permselectivity. J. Membr. Biol. 71:1-10.

4. Chang, R. L., I. F. Ueki, J. L. Troy, W. M. Deen, C. H. R. Robertson, and B. M. Brenner. 1975. Permselectivity of the glomerular capillary wall to macromolecules. II. Experimental studies in rats using neutral dextran. Biophys. J. 15:887-905.

5. Chang, R. L., W. M. Deen, C. H. R. Robertson, and B. M. Brenner. 1975. Permselectivity of the glomerular capillary wall. III. Restricted transport of polyanions. Kidney Int. 8:212-218.

6. Solez, K., R. A. Axelsen, H. Benediktson, J. F. Burdick, A. H. Cohen, R. B. Colvin, B. P. Croker, D. Droz, M. S. Dunnill, P. F. Halloran, et al. 1993. Internal standardisation of criteria for the histologic diagnosis of renal allograft rejection: the Banff working classification of kidney transplant pathology. Kidney Int. 44:411-422.

7. Guasch, A., W. M. Deen, and B. D. Myers. 1993. Charge selectivity of the glomerular filter barrier in healthy and nephrotic humans. J. Clin. Invest. 92:22742282 .

8. Mayer, G., R. A. Lafayette, J. Oliver, W. M. Deen, B. D. Myers, and T. W. Meyer. 1993. Effects of angiotensin II receptor blockade on remnant glomerular permselectivity. Kidney Int. 43:346-353.

9. Yokoyama, S., R. Hayashi, M. Satani, and A. Yamamoto. 1985. Selective removal of low density lipoprotein by plasmapheresis in familial hypercholesterolemia. Arteriosclerosis. 5:613-616.

10. Morelli, E., N. Loon, T. Meyer, W. Peters, and B. D. Myers. 1990. Effects of converting enzyme inhibition on barrier function in diabetic glomerulopathy. Diabetes. 39:76-82.

11. Golbetz, H., V. Black, O. Shemesh, and B. D. Myers. 1989. Mechanism 
of the antiproteinuric effect of indomethacin in nephrotic humans. Am. J. Physiol. 256:F44-F51.

12. Deen, W. M., C. H. R. Bridges, B. M. Brenner, and B. D. Myers. 1985. Heteroporous model of glomerular size selectivity: application to normal and nephrotic humans. Am. J. Physiol. 249:F374-F389.

13. Remuzzi, A., E. Perticucci, P. Ruggentini, L. Mosconi, M. Limonta, and G. Remuzzi. 1991. Angiotensin converting enzyme inhibition improves glomerular size selectivity in IgA nephropathy. Kidney Int. 39:1267-1273.

14. Artero, M., C. Biava, W. Amend, S. Tomlanovich, and F. Vincentini. 1992. Recurrent focal glomerulosclerosis: natural history and response to therapy. Am. J. Med. 92:375-383.

15. Bennet, C. M., R. J. Glassock, R. L. S. Chang, W. M. Deen, C. H. R. Robertson, and B. M. Brenner. 1976. Permselectivity of the glomerular capillary wall: studies of experimental glomerulonephritis in the rat using dextran sulfate. J. Clin. Invest. 57:1287-1294.

16. Whiteside, C., K. Prutis, R. Cameron, and J. Thompson. 1989. Glomerular epithelial detachment, not reduced charge density, correlates with proteinuria in adriamycin and puromycin nephrosis. Lab. Invest. 61:650-659.

17. Miller, P. L., J. Scholey, H. Rennke, and T. Meyer. 1990. Glomerular hypertrophy aggravates epithelial cell injury in nephrotic rats. J. Clin. Invest. 85:1119-1126.

18. Lafayette, R. A., G. Mayer, and T. Meyer. 1993. The effect of blood pressure reduction on cyclosporine nephrotoxicity in the rat. J. Am. Soc. Nephrol. 3:1892-1899.
19. Deckert, T., A. Kofoed-Enevoldsen, P. Vidal, K. Norgaard, H. B. Andreasen, and B. Feldt-Rasmussen. 1993. Size and charge selectivity of glomerular filtration in Type 1 (insulin dependent) diabetic patients with and without albuminuria. Diabetologia. 36:244-251.

20. Scandling, J. D., V. M. Black, W. M. Deen, and B. D. Myers. 1992. Glomerular permselectivity in healthy and nephrotic humans. Adv. Nephrol. Necker Hosp. 21:159-176.

21. Taguma, Y., Y. Kitamoto, G. Futaki, H. Ueda, H. Monma, M. Ishazaki, H. Sekino, and Y. Sasaki. 1985. Effect of captopril on heavy proteinuria in azotemic diabetes. $N$. Engl. J. Med. 313:1617-1620.

22. Heeg, J. E., P. E. De Jong, G. K. Van der Hem, and D. De Zeeuw. 1987. Reduction of proteinuria by angiotensin converting enzyme inhibition. Kidney Int. 32:78-83.

23. Remuzzi, A., P. Ruggentini, L. Mosconi, V. Pata, G. Viberti, and G. Remuzzi. 1993. Effect of low dose enalapril on glomerular size selectivity in human diabetic nephropathy. J. Nephrol. 6:36-43.

24. Thomas, D. M., A. N. Hillis, G. A. Coles, M. Davies, and J. D. Williams. 1991. Enalapril can treat the proteinuria of membranous glomerulonephritis without detriment to systemic or renal hemodynamics. Am. J. Kidney. Dis. 18:38-43.

25. Traindl, O., S. Falger, S. Reading, M. Banyai, B. Liebisch, J. Gisinger, E. Templ, G. Mayer, and J. Kovarik. 1993. The effects of lisinopril on renal function in proteinuric renal transplant recipients. Transplantation (Baltimore). 55:1309-1313.

26. Remuzzi, G., and T. Bertani. 1990. Is glomerulosclerosis a consequence of altered glomerular permeability to macromolecules? Kidney Int. 38:384-394. 